\title{
Delayed milestones, generalized hypotonia and nystagmus: hypotonic cerebral palsy or something else?
}

\author{
*Santosh Kumar ${ }^{1}$, Deepa Singh ${ }^{1}$
}

Sri Lanka Journal of Child Health, 2017; 46(4): 373-374

DOI: http://dx.doi.org/10.4038/sljch.v46i4.8387

(Key words: Joubert syndrome, hypotonic cerebral palsy, magnetic resonance imaging, molar tooth sign, vermian hypoplasia)

\section{Introduction}

Joubert syndrome (JS) is a rare clinical and autosomal recessive genetic disorder. Clinical characteristics of classic JS are frequently described as infantile hypotonia, stunted growth/mental retardation, abnormal breathing patterns and abnormal eye movements ${ }^{1}$. It is associated with failure of fibre decussation in the superior cerebellar peduncles and pyramidal tracts and varying degrees of vermian agenesis $^{2}$

Cerebral palsy (CP) is a group of disorders mainly due to a non-progressive insult to the developing brain ${ }^{3}$. Spastic CP is the most common type whereas hypotonic CP is usually rare and present in children with varying degrees of reduced tone and delayed motor milestones ${ }^{4}$. The brain MRI is very important tool to make a correlation with clinical findings in most cases of $\mathrm{CP}$ and has helped in identifying the various aetiologies 5 . Our primary objective in presenting this particular case is to highlight the importance of thorough investigations in those labelled as hypotonic CP and also to increase the database for Joubert syndrome.

\section{Case report}

An 8 month-old girl was referred to the paediatric outdoor as a case of hypotonic CP for further evaluation and management. She was born to nonconsanguineous parents after a full-term pregnancy with no significant antenatal/neonatal history. On examination, she had hypotonia, delayed milestones, squint, nystagmus and abnormal rotatory eye

\footnotetext{
${ }_{1}^{1}$ Mata Gujri Memorial Medical College and LSK hospital, Kishanganj, Bihar, India

*Correspondence: santoshaiims08@gmail.com

(Received on 16 June 2016: Accepted after revision on 15 July 2016)

The authors declare that there are no conflicts of interest

Personal funding was used for the project.

Open Access Article published under the Creative

Commons Attribution CC-BY (cc) (i)
}

movements (oculomotor apraxia). There was no facial dysmorphism, polydactyly or history of seizures. The fundus examination showed normal optic disc with mottling changes in retina. Her weight was $8 \mathrm{~kg}$ (50th centile), length was $68 \mathrm{~cm}$ (15-50th centile) and her head circumference was $46 \mathrm{~cm}\left(>95^{\text {th }}\right.$ centile for age $)$. Her developmental evaluation showed delayed milestones in all domains and overall cognitive skills were 4 months equivalent. The rest of the examination was unremarkable. At 4 months of age, she was admitted to a hospital with respiratory distress. The family history was negative for similar illness. In view of her hypotonia, developmental delay, large head, squint and nystagmus, the diagnosis of Joubert syndrome was considered. The brain MRI showed small dysmorphic clefted vermis. Axial scan showed molar tooth appearance with deep interpeduncular fossa and thickened superior cerebellar peduncle surrounding on oblong shaped fourth ventricle. (Figure 1)

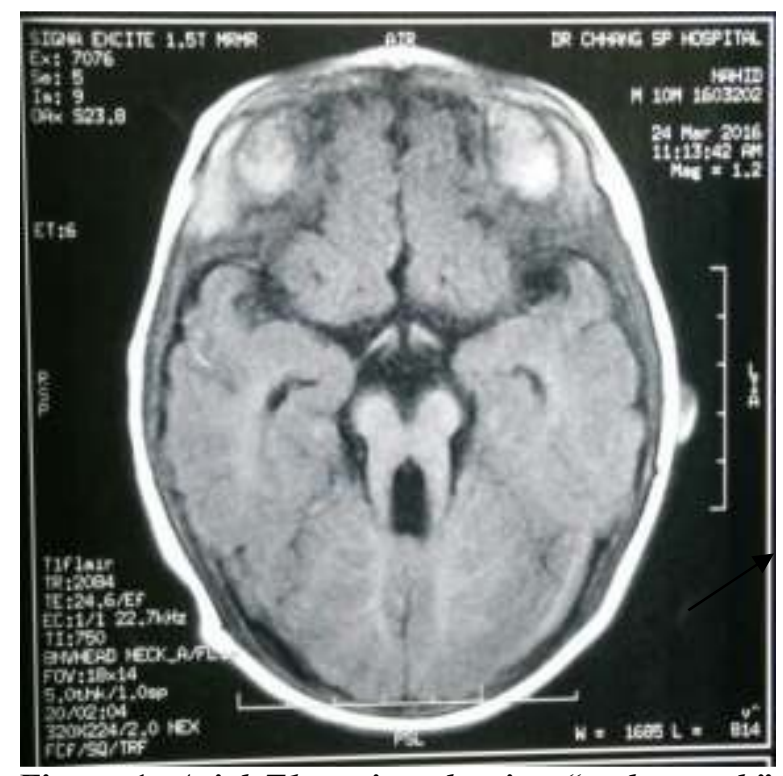

Figure 1:.Axial T1 section showing "molar tooth" appearance of midbrain due to abnormally oriented thickened superior cerebellar peduncles and a widened interpeduncular fossa 
All findings were consistent with Joubert syndrome. Ultrasound abdomen was normal. Her complete blood count, renal function tests and liver function tests were normal. She was started on a multimodality treatment with involvement of physiotherapy and was referred for genetic evaluation.

\section{Discussion}

Joubert syndrome is a heterogeneous autosomal recessive genetic condition with long-term developmental, visual, and neurological consequences. Patients present with abnormal breathing pattern, hypotonia, nystagmus, oculomotor apraxia and development delay ${ }^{5}$. Retinal dysplasia, coloboma, multicystic dysplastic kidney, hepatic fibrosis and polydactyly are other systemic associations in Joubert syndrome ${ }^{6}$. The presence of the molar tooth sign and vermian hypoplasia is a hallmark for the diagnosis of Joubert syndrome ${ }^{6}$.

Since there is overlapping clinical presentations in Joubert syndrome and hypotonic CP, there is the possibility of delayed or erroneous diagnosis, as in the present case. Joubert syndrome should be considered as differential diagnosis of hypotonic CP despite its low incidence. Joubert syndrome is associated with poor prognosis. Treatment is generally supportive, depending on the presence of neurological deficits and cognitive impairment. The brain MRI is important to make a diagnosis of JS. The prompt and early diagnosis of JS will help in identification of other associated abnormalities. Furthermore, genetic counseling is always needed in cases of JS unlike CP.

\section{References}

1. Singh P, Goraya JS, Saggar K, Ahluwalia A, et al. A report of Joubert syndrome in an infant, with literature review. Journal of Pediatric Neurosciences 2011; 6: 44-7.

PMid: 21977088 PMCid: PMC3173915
2. Spampinato MV, Kraas J, Maria BL, et al. Absence of decussation of the superior cerebellar peduncles in patients with Joubert syndrome. American Journal of Medical Genetics Part A 2008; 146A (11):1389-94. https://doi.org/10.1002/ajmg.a.32282

PMid: 18412277

3. Bax M, Goldstein M, Rosenbaum P, Leviton A, Paneth N, Dan B, et al. Proposed definition and classification of cerebral palsy, 2005. Developmental Medicine and Child Neurology 2005; 47(8):571-6. https://doi.org/10.1017/S001216220500112 $\mathrm{X}$

PMid: 16108461

4. Hagberg B, Hagberg G, Beckung E, Uvebrant $P$,et al. Changing panorama of cerebral palsy in Sweden. VIII. Prevalence and origin in the birth year period 199194. Acta Paediatrica 2001; 90:271-7. https://doi.org/10.1080/08035250130006753 2

PMid: 11332166

5. Joubert M, Eisenring JJ, Robb JP, et al. Familial agenesis of the cerebellar vermis. A syndrome of episodic hyperpnea, abnormal eye movements, ataxia and retardation. Neurology 1969; 19:813-25. https://doi.org/10.1212/WNL.19.9.813 PMid: 5816874

6. Maria BL, Hoang KB, Tusa RJ, et al. "Joubert syndrome" revisited: key ocular motor signs with magnetic resonance imaging correlation. Journal of Child Neurology 1997; 12:423-30. https://doi.org/10.1177/08830738970120070 3

PMid: 9373798 